\title{
Endemism in the Bahama Flora.
}

\author{
BY
}

\section{NORMAN TAYLOR. ${ }^{2}$}

With one Map in the Text.

SOMEWHAT over fourteen per cent of the wild flora of the Bahama $S$ Islands is confined to that archipelago. Among 894 native species scattered through the islands, 132 flowering plants are endemics, while of the balance, about 100 species are derivatives of cultivation or otherwise introduced.

While the rest of this paper will deal with the endemic flowering plants, the following is inserted to complete the known record of endemism in the archipelago :

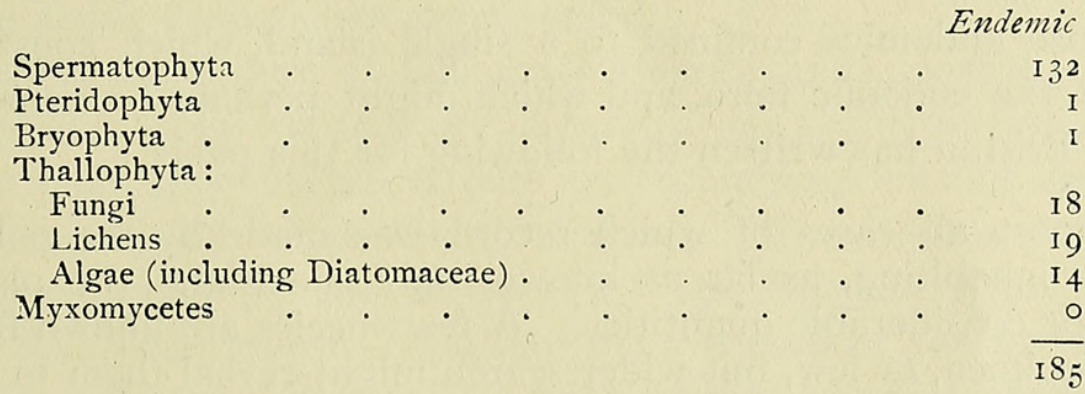

The distribution of these endemic flowering plants and their near relatives appears to throw some light upon the floristic composition of the Bahama flora and upon that of adjacent regions. Before beginning a general or specific discussion of these endemics it may not be inappropriate to record certain facts regarding them that do not coincide with the 'Age and Area' hypothesis of Dr. J. C. Willis.

The substance of that theory demands that the antiquity of endemics should be measured by the amount of area they have covered. Very rare endemics would be quite 'new' while widely dispersed ones presumably more ancient. In a paper on 'Endemism in the Flora of the Vicinity of New York' it was suggested that at least in that region the youth or

1 This study has been made possible by the recent publication of the very complete Bahama Flora by Nathaniel Lord Britton and Charles Frederick Millspaugh. To both authors I am under pleasant obligations for help in the preparation of this account of the endemics. To Dr. Britton especially my acknowledgrements are due for his interest in this study and his helpful suggestions during its progress

2 Contributions from the Brooklyn Botanic Garden, No. 25.

[Annals of Botany, Vol. XXXV. No. CXL. October, 192r.] 
antiquity of endemics could not be measured by their dispersal. For in some cases, particularly among the relicts of the pine-barrens, unquestioned antiquity goes with rather restricted distribution.

In the Bahama flora, necessarily a recent one, due to the geological youth of the islands, a somewhat detailed study of the endemics as contrasted with the non-endemic flora shows that these two floral elements are not widely different as to their dispersal.

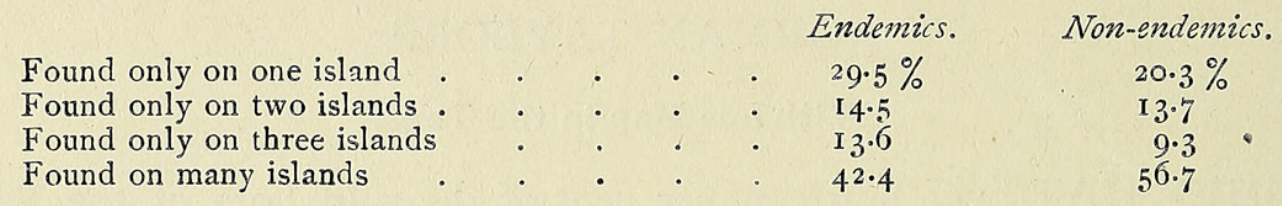

The essential similarity of these percentages warrants the statement that the dispersal of endemics in the Bahamas is not very different from that of the general flora of the archipelago. It may not be shooting beyond the mark to suggest that the dispersal, or, as Dr. Willis prefers to call it, the commonness or rarity of endemics, may be dictated by forces that play as well upon the endemic as upon the non-endemic elements of the Bahama flora.

Of those endemics confined to a single island, which constitute 29.5 per cent. of the endemic flora, and which might perhaps be considered the rarest, Dr. Britton has written the following for this paper :

'In almost all cases of which record was made by the collectors of endemics inhabiting, as far as known, only one island, the plants grow in large or considerable quantities. A few species are known from but a single specimen, or few, but wider search might reveal them in quantity.'

Both from the record of their distribution, and from the observations of those most competent to make them, it is thus apparent that the age of endemics in the Bahamas cannot be measured either by their dispersal or by their frequency.

The geological youth of the islands is reflected in the lack of endemic genera, only Neobracea, a shrub of the Apocynaceae, being peculiar to the region. If, as most students of distribution agree, endemic genera are to be considered as badges of antiquity, and they have been so interpreted in St. Helena, Galapagos, Hawaii, and hosts of isolated islands, then the lack of them in the Bahamas should brand that flora with the stigma of youth, if the geologists had not already compelled us to do so. Such a recent flora, scattered over a rather restless archipelago, so far as subsidence and emergence is concerned, ought to show among its endemics a goodly proportion of herbaceous species. For it has also been shown, for at least some regions, that endemic species in non-endemic genera are mostly herbs, which from the brevity of their life-cycle are assumed to have greater opportunity to become developed than woody plants. As the Bahamas 
are almost painfully new and have but one endemic genus, the rest of the I 32 endemics should be overwhelmingly herbaceous. How far short they come of being so is shown below.

\section{Percentages of Woody and Herbaceous Species in the Non-endemic and Endemic Elements of the Bahama Flora.}

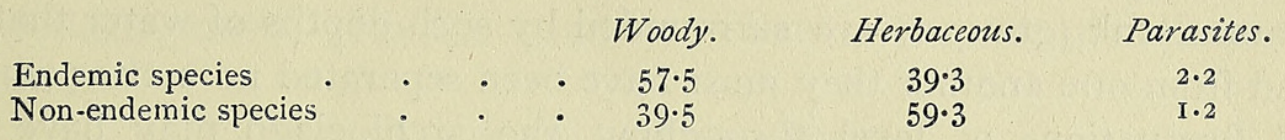

The endemic element of the Bahama flora is thus seen neither to fit into the 'Age and Area' theory of Willis, nor to accord with the theories of Sinnott and Bailey. They have argued that endemism is a criterion of antiquity, particularly where that endemism is generic, when it is sure to be represented mostly by woody species. With only a single endemic genus and on notoriously youthful islands, 57.5 per cent. of the Bahama endemics are woody! In other words, during the time that these endemic species have been developing, considerably more woody plants have arisen than herbs, notwithstanding that in the total non-endemic flora, from which they sprang, the above percentages are reversed.

Recording the failure of Bahama endemics to support the contention as to 'Age and Area' or that of 'endemism as a criterion of antiquity', apparently puts upon us the burden of accounting for the unquestioned facts of their distribution in some other way. The islands have been so thoroughly explored by the authors of 'The Bahama Flora' and their associates that what follows regarding the dispersal of the endemic plants of the archipelago may be accepted with greater certainty than is usually possible in such cases.

\section{Origin and Distribution of Bahama Endemics.}

\section{(a) The Physical Features of the Islands and their Bearing upon the Flora.}

The dispersal of the wild plants over the archipelago has first of all been affected by the structure of the islands. As the accompanying map (p. 53I) shows, there are really three groups of islands : $(\alpha)$ those that outcrop from the Little Bahama Bank, the larger of which are the islands of Great Bahama and Abaco; (b) those that outcrop from the Great Bahama Bank, notably New Providence, Eleuthera, Cat, Great Exuma, Long, and Andros islands; $(c)$ a group of scattered and isolated islands, the chief of which are Watlings, Crooked, Acklin, Mariguana, Inagua, Caicos, and Turks islands. The outstanding fact about these three groups of islands is that those on the Little Bahama Bank have several times been connected among themselves, for the water on the bank is scarcely 20 feet deep, and evidence of 
subsidence and emergence is unquestioned. Separating this group from those of the Great Bahama Bank, however, there is a passage of over five thousand feet depth. All the islands on the Great Bahama Bank are only just above the surface, the bank itself having scarcely 20 feet of water over it, so that they have been connected among themselves at some period of their history. All of the islands scattered to the southward of the Great Bahama Bank (group $c$ ) are surrounded by such depths of water that from it and from one another they must have been separated no matter what the local fluctuations of level throughout the archipelago may have been. Evidence collected by Alexander Agassiz and more recently by the Geographical Society of Baltimore puts the extreme changes of level throughout the islands as not over 200 feet. The oceanic depths between the Little Bahama and Great Bahama Banks and scattered islands to the southward are so great that no dry land connexion between them could have been possible. The authors of 'The Bahama Flora' say in the introduction to it, "There is no evidence that there ever was land connexion with either Florida, Cuba, or Hispaniola' [Haiti], a statement abundantly justified by ocean depths often in excess of twelve hundred feet and not infrequently of over ten thousand feet.

The amount of emergence and subsidence of the islands is pretty accurately known, especially from the study of the ocean holes on the banks. The depths of even the shallowest of these indicate that at some period in the past, and not so very long ago, the archipelago must have risen so far out of the water that the Bahamas must then have consisted of one large island to the north, the Little Bahama Bank of to-day, another and much larger island to the south, the Great Bahama Bank, and a group of isolated islands to the southward, never connected with either of these large land masses, nor with each other. The largest of the group is Inagua.

The present Bahamas consist of wind and sea borne material piled up at the time of this emergence, all the area within the dotted lines on the map having since been covered by the sea, except for the islands exposed at present, the 66I cays, and thousands of rocks, almost awash, that make navigation so perilous.

\section{(b) Origin of Endemics.}

With only a single endemic genus, all the rest of the endemic species are in genera that are found either on the Florida mainland, the larger West Indies to the southward, or in many cases from more remote regions.

Of the 76 genera in which all the Bahama endemics are found, except the endemic genus Neobracea, 47, or 63 per cent., are genera mostly containing numerous species of rather wide distribution. Nineteen, or 25 per cent., are genera found only in the West Indies or adjacent South 
America, while 7 per cent. of Bahama endemics are found in genera that so far as known are confined otherwise to the Florida mainland. There also appears to be about 5 per cent. of genera containing endemics which are confined to the Florida-Bahama-West Indies region, and if this study were more extensive geographically they would be considered endemic genera. They are all woody plants. These Floridian-BahamianWest Indian genera, with the number of Bahamian endemic species, are as follows :

Torribia with I Bahama endemic
Rhacoma ", I $\quad$,
Malache " I
Ernodea ", 4 ",

These 76 genera, together with those in which no endemic species are found, make up the present flora of the Bahamas. As we have shown above, the distribution of this flora, both endemic and non-endemic, does not differ greatly, nor does there appear to be any reason why there should be any fundamental difference in the forces that have controlled the distribution of these plants over the archipelago. There can be no essential age difference so far as occupancy of the islands by their flora is concerned, whether the genera happen to contain endemics or not.

The present distribution of the endemics presents certain features that demand further study in the field. Recorded below are the percentages found in the different regions of the Bahamas, followed by a brief discussion of what these figures appear to indicate. It should be borne in mind that Great Bahama Bank and Little Bahama Bank include all the islands now exposed on them. As we have shown, the individual islands in either of these groups must have once been connected with one another but not with those of the other group. Nor has there ever been any connexion of either group with the scattered and isolated islands to the south. The percentages are as follows :

\section{Distribution of Bahama Endemics on Islands of the Little Bahama Bank, Great Bahama Bank, or on Isolated Islands.}

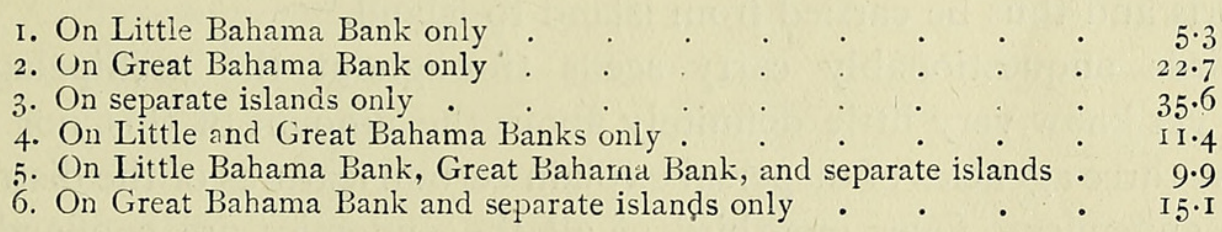

These percentages show some interesting features of the dispersal of endemics. In the first place the largest land mass, the Great Bahama Bank, has only 22.7 per cent. of the total endemics that are peculiar to it and now confined to the islands that outcrop from it. The second largest land mass, represented by the islands on the Little Bahama Bank, has only 5.3 per cent. of the total endemic flora of the archipelago. In other words, 
72 per cent. of Bahama endemics (the last four items in the tabulation) are at the present time so distributed that they are found in essentially the same form in several places that have never been connected, and often separated by tremendous depths of the ocean. This fact is still further emphasized by the $35^{\circ} 6$ per cent. of the total endemics which are confined to the group of isolated islands. Thus nearly three-quarters of the endemics show, by their dispersal over these islands, that $(a)$ they may be relicts, which is somewhat confuted by the small number of endemics found all over the archipelago, less than Io per cent.; (b) parallel evolution might account for them, although there is no evidence for or against such a theory, except possibly the great general similarity of habitat on practically all the islands; or $(c)$ certain of these island's may always have supported these and other species, and from which they spread and may still be spreading.

As to the method of dispersal, the West Indian hurricanes have, as the record for the last forty years indicates, passed through the Bahamas in a generally north-westerly direction, but except for local effects such as the case of the 'Hurricane Grass', Fimbristylis spathacea, their action is assumed rather than proven. Studies in the field as to frequency of occurrence on different islands, on windward and leeward sides of the same island, upon the air-buoyancy of fruits and seeds, their times of ripening and falling as contrasted with the hurricane season, and some other matters, are necessary in order to make, definite statements about the response of the Bahama flora to these violent storms. They are so tremendous in their ability to suck up small objects into the vortex, and move with such regularity about $\mathrm{I} 2$ to $\mathrm{I} 4 \mathrm{miles}$ an hour, and in such definite paths, that it would be surprising if they have not left their mark upon plant distribution. What that may have been demands further field study.

The Gulf Stream washes all the western side of the archipelago, but, without field studies of the ability of the seeds to both float and retain germinating power, such as the coco-nut is known to do, we can only conjecture about the influence of this great current. This applies not only to seeds that float directly, but to those that may become fastened to logs or débris and thus be carried from island to island.

Birds unquestionably carry seeds throughout the archipelago, but we as yet know very little definitely about the amount of this, nor do any of these three agencies of dispersal explain certain features of the distribution of the endemics. Over one-third of all the endemics are confined to the islands to the southward. With the Gulf Stream and hurricanes both moving past these islands in a north-westerly direction and yet failing to carry to a single island or key of the Great Bahama or Little Bahama Banks one of these southerly endemics, it is clear that the distribution of Bahama plants cannot be ascribed too readily to these agencies. Fifteen per cent. of all endemics, however, are found both on the Great Bahama 
Bank and on the isolated southerly islands, while nearly ro per cent. are found throughout the archipelago. That some of these have been distributed by the hurricanes or by the Gulf Stream is more than likely. But a comparison of them shows that they are often in genera which are also represented by the southerly island endemics which have failed to be so distributed.

While a fairly good case could doubtless be made out for parallel evolution as an explanation of similar endemics on geologically and edaphically similar but unconnected islands, proof of it is so far lacking. As suggested by Dr. Britton, the endemics of the Bahamas may be due to extreme isolation on certain islands which are very specialized by having peculiarly rocky and sterile soil, by the violence of the regular trade-wind which depresses the vegetation, and by the periodic hurricanes of most destructive force. If these factors have had any bearing upon the distribution of Bahamian endemics they should be better illustrated on the island of Inagua (including Little Inagua) than on almost any other.

It is the largest land mass of any of those southerly islands that have always been isolated by the great depth of the sea. Upon it grow a greater proportion of endemic plants than on any other island in the archipelago49 , of which +3 are confined to it. Andros, which is thrice larger, has only 5 endemics that are restricted to it, Long Island 4 , and most of the rest of the islands one or no endemic peculiar to them. Inagua is thus seen to be not only abnormally rich in endemics, which comprise $2 \mathrm{I} \cdot 4$ per cent. of its recorded flora as against 14 per cent. for the whole archipelago, but it also has a higher proportion of endemics peculiar to it than any other island. Such a combination of circumstances warrants some special study of what these plants are. The list of endemics confined to Inagua or Little Inagua follows, together with some notes upon them.

\begin{tabular}{|c|c|c|}
\hline $\begin{array}{c}\text { Endemics confined to Inagua } \\
\text { or Little Inagua. }\end{array}$ & $\begin{array}{c}\text { Number of Endemic } \\
\text { Species in the same } \\
\text { Genus, but in other } \\
\text { Parts of the } \\
\text { Archipelago. }\end{array}$ & $\begin{array}{l}\text { Total Number of } \\
\text { Species known from } \\
\text { the Bahamas. }\end{array}$ \\
\hline Dichromena inaguensis & 0 & 2 \\
\hline Agave Nashii & 7 & 8 \\
\hline Encyclia inaguensis & I & 8 \\
\hline Heliotropium Nashii & 4 & IO \\
\hline Lantana balsamifera & I & 6 \\
\hline $\begin{array}{l}\text { Nashia ina uensis } \\
\text { Guettarda Taylori }\end{array}$ & 0 & I \\
\hline Guettarda Nashii & $\circ$ & 6 \\
\hline $\left.\begin{array}{l}\text { Ernodea Taylori } \\
\text { Ernodea Nashii }\end{array}\right\}$ & 2 & 6 \\
\hline Borreria inaguensis & 5 & 8 \\
\hline Vernonia obcordata & 3 & 5 \\
\hline
\end{tabular}

The ten genera in which these thirteen endemics peculiar to Inagua are found are distributed otherwise in the following way: 
Dichromena has only one other Bahamian species, D. colorata, which is widely distributed both throughout the archipelago, on the mainland, and in the larger West Indies. It is found on Inagua, and must be the parent or source of the endemic $D$. inaguensis.

Agave has eight native species in the Bahamas, all endemics, which are scattered over the archipelago thus :

A. inaguensis on Little Inagua and on Caicos.

A. bahamana on several islands, all on Great Bahama Bank.

A. Millspanghii, confined to Great Exuma.

A. cacozela, confined to New Providence.

A. acklinicola, confined to Acklin Island.

A. indagatorum, confined to Watlings Island.

A. Braceana, on Abaco, Great Bahama, and doubtfully on Andros. Encyclia has eight species in the Bahamas, with only one other endemic, $E$. bahamensis, which is found nearly throughout the archipelago and also on Inagua. E.diurna and E.plicata, both widely distributed in the Bahamas and elsewhere, are also found on Inagua. It is difficult to avoid the conclusion that from these three Encyclias, known to grow on Inagua, the endemic E. inaguensis has been derived.

Heliotropium has ten species in the Bahamas, of which five are endemic. Of these endemics only two others are known on Inagua, while three common Bahamian Heliotropiums are also found there.

Lantana has six species in the Bahamas, two of which are endemic. $L$. demutata is an endemic confined to the islands on the Great Bahama Bank. On Inagua are recorded L. Camara and L. involucrata, from the latter of which $L$. balsamifera may be safely assumed to have been derived, as it is a plant of wide distribution nearly throughout the West Indies.

Nashia has only a single species in the Bahamas, the endemic $N$. inaguensis, confined to that island. Two other species are known in the larger West Indies.

Guettarda has six Bahamian species, with all its three endemics confined to Inagua. The other three species, all found on Inagua also, are of wide distribution both in the Bahamas, the Florida mainland, and in the West Indies.

Ernodea has six Bahamian species, four of which are endemic. Two of these endemics are unknown on Inagua, but $E$. littoralis, a species of wide distribution, is common there. E. Nashii and E. Taylori must have been derived from it, for these comprise all the Ernodeas known on the island.

Borreria has eight species in the Bahamas, six of which are endemics. Of these endemics $B$. savannarum and B. bahamensis are found on Inagua as well as other islands, while the only widely distributed species found on the island is B. laevis. 
Vernonia has five species in the Bahamas, four endemics among them. No other Vernonia is known on Inagua but the widely distributed $V$. bahamensis, which is also endemic in the archipelago, and from which the endemic $V$. obcordata peculiar to Inagua must have been derived.

In all these ten genera, except Agave and Nashia, it is difficult to avoid the conclusion that endemics peculiar to Inagua have been derived from other and much more widely distributed species also known to grow there. Agave, with all its species endemic, and only one of which besides A. Nashii is also found on Inagua, is a peculiar case. In this genus

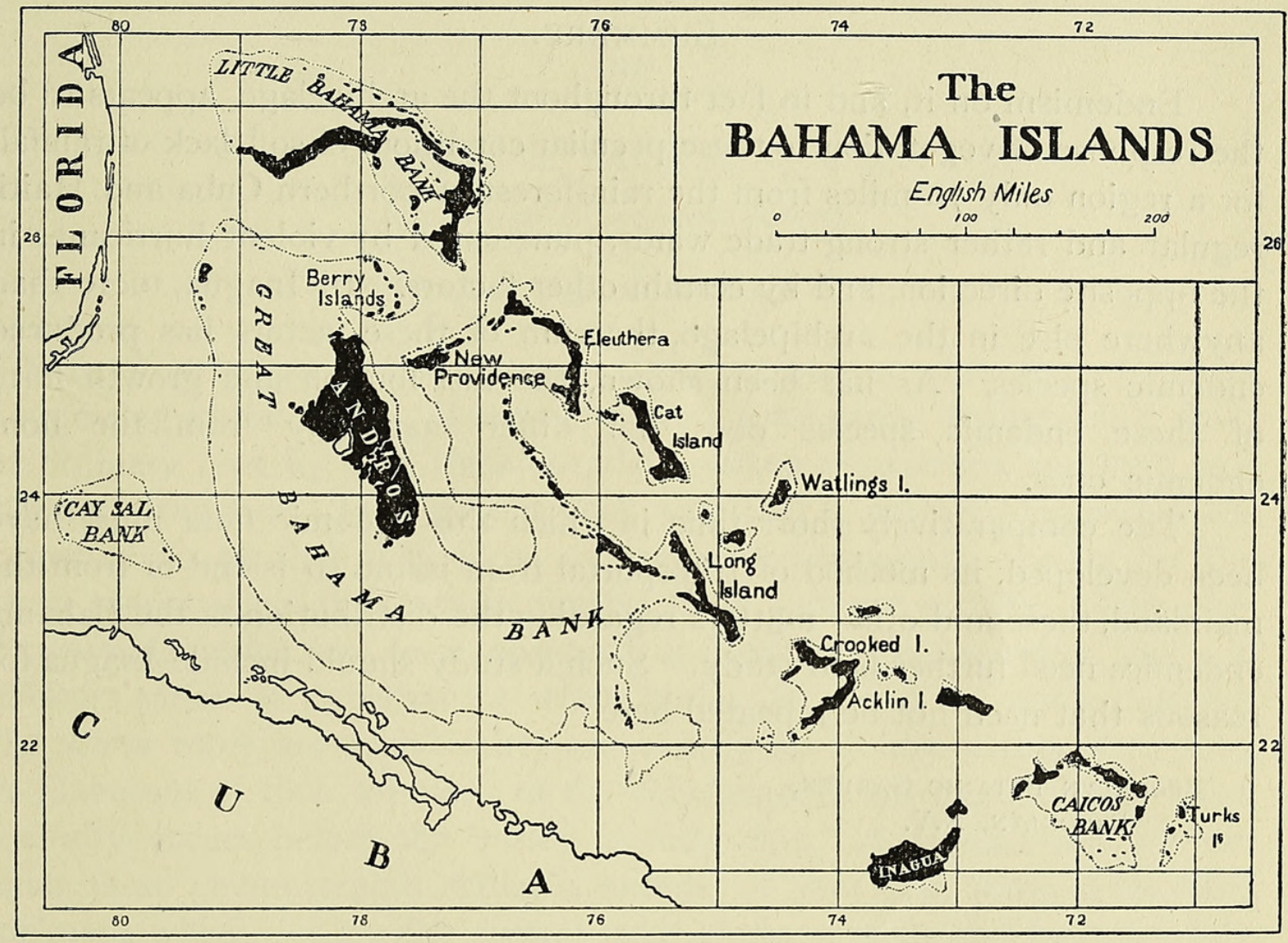

Note the dotted lines that mark the limits of the old land masses of the Bahamas, now represented by the Banks and the scattered islands.

we are confronted with a wealth of scattered progeny but a dearth of parents. The most widely distributed endemic is $A$. bahamana, but it is unknown from Inagua, and is so far recorded only from the islands on the Great Bahama Bank. In other words, we are faced with two endemic century plants on Inagua, and with Nashia inaguensis, none of which have any relatives now on the island from which they could have been derived.

There is, of course, always the chance that the progenitors of these endemic century plants and of Nashia have failed of survival, and that these endemics and others in the archipelago represent the end-series of a pre-existing flora, which the great specialization of habitat has produced. The sterility of the soil, limited rainfall (salt is recovered by evaporation of 
sea-water in several islands), and the saline soil conditions in many others are reflected in a generally depressed vegetation with many adjustments to prevent transpiration. A field study of the origin and distribution of the flora of Inagua and some of the limiting factors would throw much light on this problem. The study of the records of 'The Bahama Flora' shows Inagua to be higher in endemic species than any other island in the archipelago. It is the largest land mass of any of the isolated islands, and there is in the interior of it a good-sized salt lake and savannah region. These combinations of special conditions, reflected in its flora as they are known to be, make it worth additional field study.

\section{Summary.}

Endemism on it, and in fact throughout the archipelago, appears to be the response of vegetation to these peculiar conditions of soil, lack of rainfall for a region only 70 miles from the rain-forest of northern Cuba and Haiti, regular and rather strong trade winds, punctuated by violent hurricanes in the opposite direction, and by certain other factors. In Inagua, more than anywhere else in the archipelago, the sum of these factors has produced endemic species. As has been shown, the distribution and growth form of these endemic species does not differ materially from the nonendemic ones.

The comparatively short time in which this endemic flora must have been developed, its method of transportal from island to island or from the mainland, these and other matters regarding the distribution of the Bahama endemics need further field study. Such a study should include Inagua for reasons that need not be repeated here.

Brooklyn Botanic Garden,

BROOKLYN, N.Y.

\section{LITERATURE.}

Agassiz, A. (1894): Reconnaissance of the Bahama Islands. Bull. Mus. Comp. Zool., Harvard Coll., xxvi. I-203.

Geographical Society of Baltimore (1905): The Bahama Islands, pp. i-630.

Sinnott, E. W. (1917): The 'Age and Area' Hypothesis and the Problem of Endemism. Ann. Bot., xxxi. 2 10-16.

, and Balley, T. W. (1914): The Origin and Dispersal of Herbaceous Angiosperms. Ibid., xxviii. 547-600.

Taylor, N. (1916): Endemism in the Flora of the Vicinity of New York. Torreya, xvi. I8-27.

Willis, J. C. (1915): The Endemic Flora of Ceylon, with Reference to Geographical Distribution and Evolution in general. Phil. Trans. Roy. Soc., Series B, ccvi. 307-42.

(1916): The Evolution of Species in Ceylon, with Reference to the Dying Out of Species. Ann. Bot., xxx. I-23.

xxi. $189-208$. 


\section{$2 \mathrm{BHL}$ Biodiversity Heritage Library}

Mahler, D. Luke. 1921. "Endemism in the Bahama flora." Annals of botany 35, 523-532. https://doi.org/10.1093/oxfordjournals.aob.a089774.

View This Item Online: https://www.biodiversitylibrary.org/item/235780

DOI: https://doi.org/10.1093/oxfordjournals.aob.a089774

Permalink: https://www.biodiversitylibrary.org/partpdf/319017

\section{Holding Institution}

Smithsonian Libraries

\section{Sponsored by}

Biodiversity Heritage Library

\section{Copyright \& Reuse}

Copyright Status: Not in copyright. The BHL knows of no copyright restrictions on this item.

This document was created from content at the Biodiversity Heritage Library, the world's largest open access digital library for biodiversity literature and archives. Visit BHL at https://www.biodiversitylibrary.org. 